\title{
Mass Spectrometry and Fullerenes
}

\author{
Stephen W. McElvany and Mark M. Ross \\ Chemistry Division, Naval Research Laboratory, Washington, DC, USA
}

\begin{abstract}
This article presents, from a mass spectrometry perspective, an historical account of research on gas-phase carbon clusters, which has led to the discovery of another form of carbon, fullerenes, In addition, more recent mass spectrometric studies on analysis of fullerene derivatives and synthesis of doped fullerenes are described. The early, strong evidence for certain "magic number" carbon clusters, most notably $\mathrm{C}_{60}$ (buckminsterfullerene), was obtained largely from mass spectrometric experiments. These studies led to the controversial postulation of the soccerball structure for $\mathrm{C}_{60}$, which provoked increased experimental and theoretical efforts. This research eventually resulted in the discovery of a simple method by which large quantities of fullerenes can be produced. The availability of these new, all-carbon molecules has motivated a broad range of synthetic and characterization studies that are expanding at a frenetic pace. Mass spectrometry not only played a critical role in the discovery of fullerenes but also now is crucial for determination of the unusual chemical and physical properties of fullerenes and fullerene-based materials. ( $\mathrm{Am}$ Soc Mass Spectrom 1992, 3, 268-280)
\end{abstract}

$\mathrm{O}$ ne of the most rapidly expanding and exciting areas of scientific research today is centered on the newly discovered family of all-carbon molecules, fullerenes. Until a little more than a year and a half ago these species were observed and studied only in the gas phase and were called carbon clusters. The indirect evidence of the structures and properties of carbon clusters was obtained almost entirely from mass spectrometric experiments. These studies motivated the prophetic, yet controversial, postulation by Kroto and Smalley that the even-numbered $C_{n}$ species with $n \geq 32$ had spheroidal structures and, in particular, the anomalously abundant and unreactive $n=60$ cluster had a truncated icosahedral (soccerball) structure (Figure 1). These ideas were the subject of intense debate for several years, until recently when Huffman and Krätschmer demonstrated a simple method by which macroscopic quantities of these clusters could be produced. This enabled numerous studies that verified the earlier hypotheses on these fullerenes. More importantly, a new form of carbon, which can be dissolved, sublimed, manipulated and derivatized, is readily available and an exciting area of scientific research has emerged.

There are several recent reviews covering the research on carbon clusters both leading up to and including the synthesis of macroscopic quantities of fullerenes [1-4]. The reviews by Kroto, Smalley, and

Address reprint requests to Mark M. Ross, Chemistry Division/Code 6113, Naval Research Laboratory, Washington, DC 20375-5000. their co-workers [1-3] provide an excellent first-hand perspective on the discovery, postulation of structures (including early references on the fascination of such symmetrical species) and characterization of fullerenes. One of the unique aspects in the development of fullerenes is that mass spectrometry, which is commonly used as an analytical method for bulk samples, played a critical role in the discovery and early characterization of these species in the gas phase, which has in turn resulted in their synthesis in bulk quantities. This article provides a mass spectrometrist's perspective and account of the chronology of research that led to the discovery of fullerenes and describes the more recent efforts on mass spectrometric synthesis and characterization of fullerenes and derivatized fullerenes.

\section{Carbon: The Early Years}

Numerous mass spectrometric studies reported the production and limited characterization of small carbon clusters, $C_{n}(n<32)$, for over 40 years prior to the observation of the larger "fullerene" cluster ions $(n>32)$ in 1984. Mattauch et al. [5] in 1943 first observed $\mathrm{C}_{n}^{+}$up to $n=15$ as background signal in the isotopic analysis of various metals and metal oxides. The first detailed $C_{n}^{+}$studies were reported by Dörnenburg et al. in 1959 [6] and 1961 [7] in which $C_{n}^{+}$ were generated by a high-frequency carbon arc followed by mass analysis in a normal geometry (EB) sector instrument. The production of singly and multiply charged carbon clusters was observed up to $n=28$ with enhanced abundances for $C_{n}^{+}$with $n=7$, 11,15 , etc. In addition to the $\Delta n=4$ periodicity for 


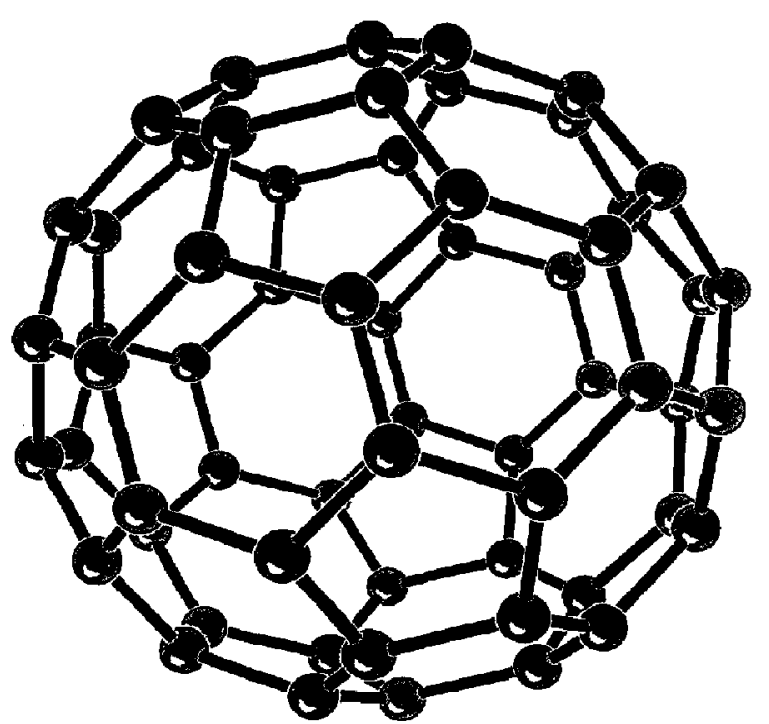

Figure 1. Structure of $C_{60}$, Buckminsterfullerene.

the small carbon clusters, they also observed the predominance of neutral $\mathrm{C}_{3}$ loss in metastable decompositions, which has been reported in numerous more recent tandem mass spectrometry studies discussed below. Electron ionization (EI) of carbon vapor over heated graphite was found to produce only small ( $n<7$ ) clusters and resulted in $\Delta H_{f}$ estimations for neutral $C_{n}$ species by measuring the change in $\log P$ versus $1 / \mathrm{T}[8,9]$.

The use of other methods for production of carbon cluster ions followed in the early 1960 s with the accelerated development of surface analysis techniques and methods for ion generation from solids. Honig [10] reported that secondary ion mass spectrometry (SIMS) of graphite and other carbon-containing solids produces negative ions, $C_{n}^{-}(n<12)$, with enhanced abundances for even-numbered clusters due to their greater stability as anions (high electron affinity). In contrast, the absence of significant $C_{n}^{+}$produced by SIMS was attributed to their relatively high ionization potentials. The first laser vaporization study of graphite was reported by Berkowitz and Chupka [11] and showed a similar distribution to the previous studies for $C_{n}^{+}$up to $n=14$. More recently, the laser microprobe technique (LAMMA) was used, which showed abundant production of both positively- ( $n<$ 25) and negatively- $(n<13)$ charged carbon clusters [12]. As will be evident in the following section, laser vaporization for the production of carbon clusters dominates the studies after 1985 due to its versatility, high output, and pulsed nature which facilitates coupling with molecular beam sources and pulsed mass spectrometry techniques, e.g., time-of-flight mass spectrometry (TOF-MS) and Fourier transform ion cyclotron resonance mass spectrometry (FTICR or FTMS).

\section{Discovery of $\mathbf{C}_{60}$ and Fullerenes}

The entire area of cluster research was revolutionized with the development of the laser vaporization molecular beam (LVMB) source by Smalley and co-workers in 1981 [13]. Briefly, the focussed output of a high-energy pulsed laser ablates material from a rotating sample of interest in the throat of a pulsed valve. The small neutral and charged species are entrained by the high-density helium pulse and undergo clustering reactions and subsequent cooling in the supersonic expansion into the vacuum system. The output typically passes through a skimmer and the nascent ions or photoionized neutrals are mass analyzed, usually by TOF-MS. These sources efficiently produce clusters of up to several hundred atoms from virtually any element or heterogeneous material.

The particular advantage of the LVMB source is the ability to produce metal clusters that are typically not generated by direct laser vaporization (DLV) of the bulk metal into vacuum. It was not until 1984, however, that carbon was studied in this type of apparatus by the Exxon group [14], which produced the photoionization mass spectrum of carbon clusters shown in Figure 2a. The small $C_{n}^{+}(n<30)$ distribution was similar to that previously observed, but this was the furst observation of the large $C_{n}^{+}(n=40-200)$. Interestingly, only the even-numbered cluster ions were observed for $n>40$, which was considered consistent with a proposed carbyne form of carbon that contains alternating single and triple bonds. The emphasis of this furst study was on the unique bimodal cluster distribution seen in Figure 2a, which is not observed for clusters of any other element. The ionization potentials of the clusters were estimated by threshold photoionization studies, which also suggested that the two distributions ( $n<30 ; n>40$ ) have different origins. The group at Bell Laboratories in 1985 [15] studied both the nascent ions (positive and negative) and photoionized neutrals generated in an LVMB cluster source. Photoionization resulted in a distribution similar to that in Figure 2a, although the nascent cations did not exhibit the bimodal behavior or the presence of only even-numbered cluster ions for $n>40$. Although no particular mention was made of the structure/stability of $\mathrm{C}_{60}$, they did report the furst tandem mass spectrometry (TOF) study on the photodissociation of $\mathrm{C}_{60}$.

It was not until late in $\mathbf{1 9 8 5}$ that the unique stability of $C_{60}$ (and $C_{70}$ ) was experimentally observed in collaborative studies by Kroto (University of Sussex) and Smalley and co-workers at Rice University [16]. In addition to reproducing the cluster distribution shown in Figure 2a, the expansion conditions were altered to maximize thermalization and cluster reactions (Figure 2b) that showed the remarkable stability of the $n=60$ and 70 cluster ions relative to their neighbors. The structure of the unique $C_{60}$ magic number cluster was proposed to have the truncated icosahedral structure of a soccerball with carbon atoms at its vertices, con- 
a

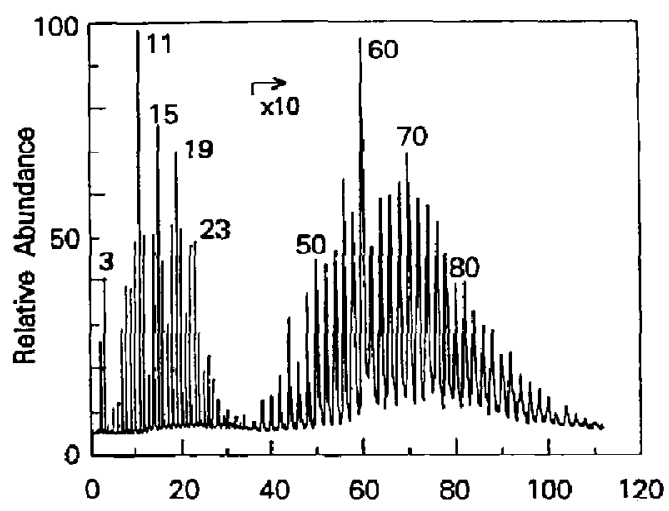

b

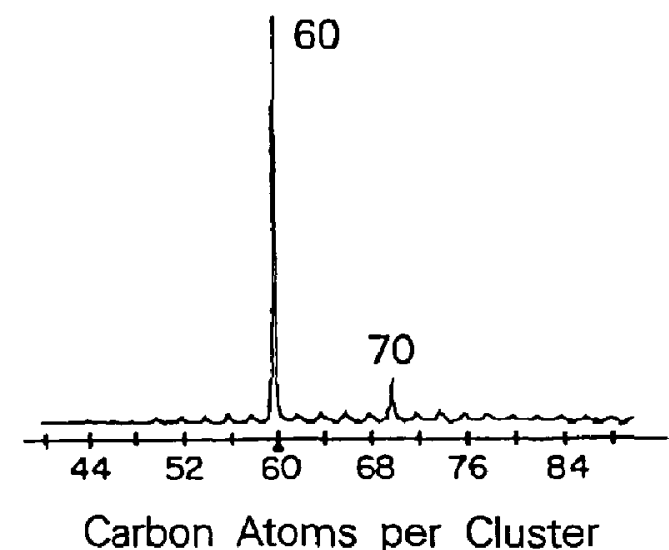

Figure 2. Laser vaporization molecular beam time-of-flight mass spectrum of photoionized carbon cluster ions $\left(C_{n}^{1}\right)$ as observed by (a) the Exxon group (Reprinted with permission from ref. 14. Copyright 1984 American Institute of Physics), and (b) the Rice group, in which the beam expansion conditions were optimized for clustering and thermalizing reactions. (Reprinted by permission from NATURE vol. 318 pp. 162-163 Copyright (c) 1985 Macmillan Magazines Ltd., ref. 16).

sisting of 12 pentagons and 20 hexagons. The remarkable nature of the $C_{60}$ cluster seemed consistent with this model in that it is the smallest such species in which there are no adjacent pentagons and thus every carbon atom is equivalent in the perfectly symmetrical structure (see Figure 1). The $C_{60}$ species was given the name buckminsterfullerene from the work of $R$. Buckminster Fuller on the design and stable nature of spheroidal structures which contain both five- (which result in the curvature of hexagonal graphitic sheets) and six-member rings. The other even-numbered carbon clusters $(n>32)$ were also suggested to be spheroidal resulting in the "fullerene" nomenclature for this entire class of clusters. Many of the unique aspects of buckminsterfullerene that are still being investigated today were proposed in this prophetic Kroto/Smalley paper including its possible presence in interstellar clouds and its role as the carrier of unassigned diffuse interstellar lines (DILs); unique properties when a metal is encapsulated in the cage; and derivatization to generate a possible super-lubricant $\left(\mathrm{C}_{60} \mathrm{~F}_{60}\right)$. Shortly thereafter, the production of gas-phase lanthanum complexes of fullerenes was reported [17], but it was several years before their structures were characterized by photodissociation.

\section{Fullerenes: The Early Years}

In the next few years (1986-1987) the number of experimental groups working on carbon clusters remained small but the effort intensified to obtain as much indirect structural information on these species as possible from gas-phase experiments using mass spectrometry. The increased interest in these studies was at least in part due to attempts to prove or disprove the unique and almost unbelievable proposed soccerball structure of $C_{60}$. These experiments continued to examine the formation of large carbon clusters in addition to using tandem mass spectrometry to measure their fragmentation hehavior and other gas-phase properties.

There was much debate whether the carbon cluster ion distributions observed were conclusive evidence for the proposed structure. The Exxon group reported several detailed studies of the effect of photoionization conditions on the observed mass spectra; the results put in question the absolute abundances of the nascent neutral $C_{60}$ and $C_{70}$ clusters [18] as well as metal complexes $[18,19]$. In addition to the dependence of the $C_{n}^{+}$distribution on growth conditions in the cluster source and photoionization conditions, similar behavior was observed for the corresponding negative ions. Postionization of the neutral cluster beam showed the even-numbered $C_{n}^{-}$with enhanced $n=60$ and 70 as in the positive ion distribution [20]. Whetten and co-workers [21] reported that the distribution of nascent anions from an LVMB source exhibited no magic numbers with both even and odd $C_{n}^{-}$ $(n=40-80)$ observed under the same conditions in which $\mathrm{C}_{60}^{+}$and $\mathrm{C}_{70}^{+}$were enhanced in the nascent positive ions. This again suggested that the anomalies in the cluster distribution may result from photoinduced processes (i.e., fragmentation or ionization cross-section differences). Subsequent experiments [22], however, showed once again that the $n=60$ and 70 clusters were enhanced as nascent anions under high-pressure conditions in the nozzle, which induce clustering and that these anions are less reactive than the surrounding cluster sizes. It was also shown by fluence studies in photoionization that fragmentation processes do not account for the enhanced $C_{60}^{+}$and $C_{70}^{+}$, although differences in ionization cross section could not be ruled out for the enhancement of these magic numbers at threshold ionization conditions. The reactivity of neutral carbon clusters was examined by adding reactant gases downstream from 
the nozzle in a fast flow reaction tube [23, 24]. The reaction products were then photoionized and detected by TOF-MS. The small $(n<30)$ neutral carbon clusters and large $(n>30)$ odd clusters were found to be quite reactive with a variety of reactants (e.g., NO, $\mathrm{SO}_{2}$, and $\mathrm{CO}$ ). In contrast, the large $(n>30)$ evennumbered clusters were found to be relatively inert, and $C_{60}$ is almost completely unreactive and surviving even under extreme reaction conditions. This behavior is consistent with a model in which the enhanced abundance of $C_{60}$ results from its inert nature in the growth of carbon clusters.

In 1986, the research group at the Naval Research Laboratory reported that a molecular beam expansion with helium was not necessary to generate the fullerene cations [25]. Direct laser vaporization of a stationary graphite sample into vacuum with TOF mass analysis generated a $\mathrm{C}_{n}^{+}$distribution remarkably similar to the LVMB/TOF mass spectra (see Figure 2a) but was dependent on the laser irradiation time. Initially only small $\mathrm{C}_{n}^{+}(n<30)$ were generated, but once a small channel was drilled into the sample, relatively abundant fullerene cations $(n>30)$ were observed in the mass spectrum. It was proposed that entrainment of the laser-generated plasma facilitates reactions (probably ion/molecule) which produce the larger carbon cluster ions. Interestingly, two prior studies on the production of $\mathrm{C}_{n}^{+}$and $\mathrm{C}_{n}^{-}$by DLV of graphite in an FTMS $[26,27]$ did not report the presence of fullerene ions. The bimodal $C_{n}^{+}$distribution was subsequently observed by DLV in an FTMS under certain conditions [28]. Production of the fullerene cations was dependent not only upon the irradiation time, as in the TOF-MS study, but also upon the geometric configuration of the magnetic field and the propagation of the laser-generated plasma, which is again consistent with their production via ion $/ \mathrm{mole}$ cule reactions. Although these initial FTMS studies found the fullerene cations to be unreactive and stable under low-energy collision-induced dissociation (CID) conditions, the long time-scale and higher resolution of the instrument (cf previous TOF-MS studies) demonstrated that these ions are long-lived following laser vaporization and do not contain hydrogen impurities.

The first formation of fullerene ions from a source other than LVMB or DLV of graphite was reported by Homann and co-workers [29] in a study of the nascent ions in benzene- and acetylene-oxygen flames. Both positive and negative $\mathrm{C}_{n}$ (even $n$ ) and $\mathrm{C}_{n} \mathrm{H}_{x}$ (odd $n$ ) ions were detected in the flames by TOF mass spectrometry. The role of these spheroidal carbon clusters in soot formation was proposed in several of the early Kroto/Smalley papers [23, 24] and remains a topic of intense debate $[30,31]$.

Tandem mass spectrometry played an important role in probing the physical properties of these large carbon cluster ions. The first systematic photodissociation study by Smalley and co-workers [32] used tandem TOFMS. The stability of even-numbered $C_{n}$ ( $n>32$ ) was exhibited in the high fluences required for photodissociation. A typical photodissociation spectrum of $C_{60}^{+}$is shown in Figure 3a. All even-numbered $C_{n}^{+}(n>32)$ fragment by either sequential loss of $C_{2}$ units, or more probably loss of larger evennumbered $C_{n}$, to generate smaller (even $n$ ) fullerene cations. As expected, $C_{60}^{+}$and $C_{70}^{+}$were present in enhanced abundance as fragments of large $(n>70)$ carbon cluster ions. The smallest stable fullerene was shown to be $C_{32}^{+}$which fragments to yield both even and odd small carbon clusters, $C_{n}^{+}(n=7-28)$, with the usual enhancement of $n=7,11,15$, etc. Mechanisms were discussed for both $C_{2}$ and even-numbered $C_{n}$ loss in which the daughter ions ( $n \geq 32$ ) maintained their fullerene structure. In contrast, odd $C_{n}^{+}(n>32)$ fragment by $C_{1}$ loss (and possibly odd $C_{n}$ loss) to yield only even-numbered $C_{n}^{+}$fullerene daughter ions.

The photodissociation behavior of large even-num-

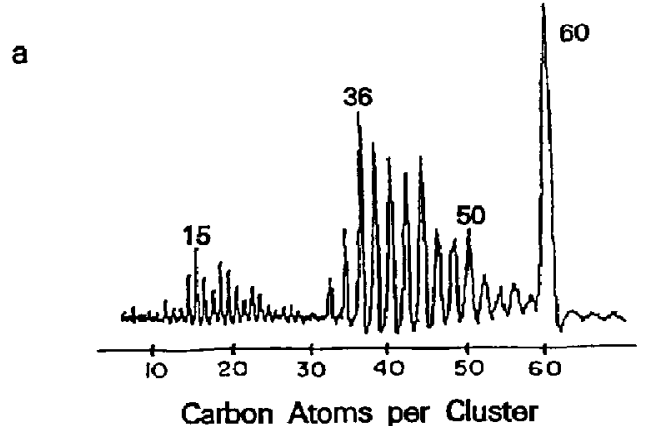

b

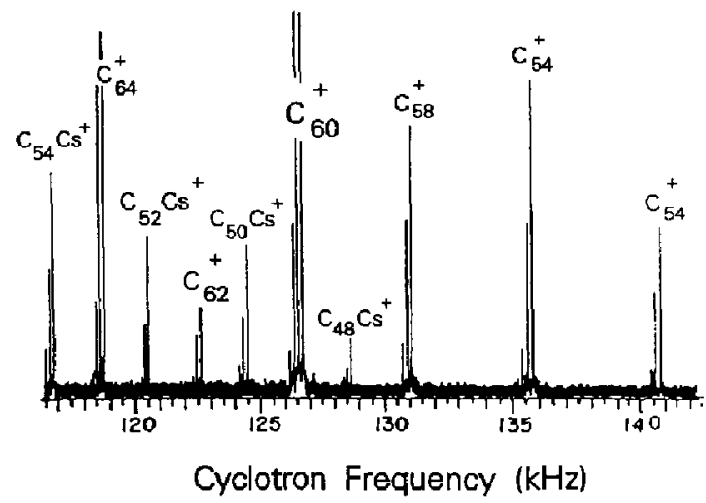

Figure 3. (a) Photodissociation $(353 \mathrm{~nm})$ time-of-flight mass spectrum of $C_{60}^{+}$, showing the photofragment ions, $C_{n}^{+}$, corresponding to $C_{2}$ losses (Reprinted with permission from ref. 32 . Copyright 1988 American Institute of Physics) and (b) photodissociation (193 nm) of $\mathrm{C}_{60} \mathrm{Cs}^{+}$and $\mathrm{C}_{72}^{+}$in an FTMS, which yields $\mathrm{C}_{n}^{+}$species (from $\mathrm{C}_{72}^{+}$) and $\mathrm{C}_{n} \mathrm{Cs}^{+}$(down to $n=48$ from $\mathrm{C}_{60} \mathrm{Cs}^{+}$) resulting from $\mathrm{C}_{2}$ losses. (Reprinted with permission from ref 33. Copyright 1988 American Chemical Society.) (Note that the FTMS mass spectrum (b) is plotted in frequency which is inversely proportional to mass.) 
bered $\mathrm{C}_{n}^{+}$is consistent with the proposed fullerene structures, but the most convincing experimental evidence for their spheroidal structure came in the fragmentation of the corresponding metal complexes [33]. These studies were performed on $\mathrm{C}_{n} \mathrm{M}^{+}$generated in an external LVMB cluster source and injected into an FTMS [34]. Photodissociation of $\mathrm{C}_{n} \mathrm{M}^{+}$species resulted in $C_{2}$ loss as with pure $C_{n}^{+}$, as opposed to simply fragmentation to $\mathrm{C}_{n}^{+}$or $\mathrm{M}^{+}$, which would be expected for an externally bound adduct. The endpoint for $\mathrm{C}_{2}$ loss was higher for $\mathrm{C}_{n} \mathrm{M}^{+}$than $\mathrm{C}_{n}^{+}$(at $n=32$ ) as shown for $\mathrm{C}_{n} \mathrm{Cs}^{+}$in Figure $3 \mathrm{~b}$ in which $\mathrm{C}_{48} \mathrm{Cs}^{+}$is the smallest species observed prior to fragmentation into much smaller cluster ions. This behavior would be consistent with the metal occupying the inside of a carbon cage and systematic studies showed the $C_{2}$ loss endpoint to vary as expected with the ionic radii of the metal (e.g., at $n=44$ for $\mathrm{C}_{n} \mathrm{~K}^{+}$).

Although these mass spectrometry studies provided provocative and important information on these species, definitive structural determination would require extensive spectroscopic characterization. Prior to the availability of macroscopic amounts of these clusters, spectroscopic studies were limited to gas-phase experiments using mass spectrometry. Ultraviolet photoelectron spectroscopy of mass-selected anions showed that the $n=50,60$ and 70 clusters were the only ones possessing large HOMO-LUMO gaps and that all the clusters have relatively high electron affinities with $C_{60}$ being the lowest at $\sim 2.75 \mathrm{eV}$ [35]. The UV absorption spectrum of $C_{60}$ was probed with laser depletion spectroscopy of van der Waals complexes of $\mathrm{C}_{60}$ with $\mathrm{C}_{6} \mathrm{H}_{6}$ and $\mathrm{CH}_{2} \mathrm{Cl}_{2}$ [36]. The observation of a single narrow feature (near $3860 \AA$ ) is consistent with a rigid, highly symmetrical structure for a species this large. Most important, determination of these physical properties provided data for comparison with theoretical studies, which would be important in the eventual macroscopic isolation of fullerenes.

A wealth of chemical and structural information was also obtained on the smaller carbon cluster ions $(n<32)$ from tandem mass spectrometry studies. Photofragmentation studies using tandem TOF-MS $[37,38]$ and low-energy CID in an FTMS [39] showed that neutral $C_{3}$ loss dominates in the dissociation of the smaller cluster cations $(n=6-20)$. A large decrease in the photodissociation cross section was observed between $\mathrm{C}_{9}^{+}$and $\mathrm{C}_{10}^{+}$which was consistent with the proposed structural transition for the corresponding neutrals from linear to cyclic species. This structural change was clearly evident in the ion/molecule reactions of $\mathrm{C}_{n}^{+}$using FTMS [39-41]. The linear cluster ions $(n<10)$ undergo carbene-type reactions with a wide range of neutral species, whereas $\mathrm{C}_{n}^{+}$ $(n \geq 10)$ are essentially unreactive and consistent with the lack of carbene sites in a cyclic structure. The most striking results from the ion/molecule reactivity studies was the observation of reactive and unreactive forms of $C_{7}^{+}, C_{8}^{+}$and $C_{9}^{+}$, which was interpreted as linear and cyclic structural isomers. Although it was generally believed that isomeric species might be present in covalently bonded clusters, these studies provided the first experimental evidence for their occurrence [26] and reactivity studies continue to be used for isomer analysis in studies of metal clusters [42-46].

\section{Prelude to Bulk Fullerenes: Production and Characterization Continues}

The number of groups contributing to the area of mass spectrometry of carbon clusters increased in the years leading up to the bulk synthesis of fullerenes. A large number of studies reported the production of fullerene ions from a variety of materials with different ion production methods. A variety of polymers were shown to generate high-mass carbon cluster ions by both direct laser vaporization [47-49] and ion bombardment [50] (kiloelectronvolt SIMS and plasma desorption). The production of relatively abundant high-mass cluster ions (up to $n>600$ ) was also reported in laser ablation/desorption studies of polycyclic aromatic hydrocarbons (PAHs) [51, 52], coals [52], and benzene soot [53]. The mass spectra observed from these materials differ somewhat from the graphite laser vaporization spectra in that these other sources typically produce more abundant higher mass $C_{n}^{+}(n>100)$ but the lower $C_{n}^{+}(n<32)$ and enhanced $C_{60}^{+}$and $C_{70}^{+}$are either not observed or are quile dependent on experimental conditions. The lower mass regions usually contain ions that are indicative of the starting material (e.g., $\mathrm{PAH}$ ions or polymer fragments/clusters). Laser desorption of carbon oxides $\left(\mathrm{C}_{8 n} \mathrm{O}_{2 n}\right)$ which are precursors to all-carbon molecules also generates abundant positive and negative carbon cluster ions [54]. These results are quite intriguing but the ions generated from these materials have yet to be characterized by tandem mass spectrometry. While the results from these studies clearly demonstrate the stability and ease of formation of high-mass $C_{n}^{+}$from diverse precursors, the mechanism for their production from these materials and even from graphite $[55,56]$ remains an open question.

The metastable decompositions of $\mathrm{C}_{n}^{+}$formed by direct laser vaporization of graphite were studied by Bowers and co-workers [57-60] in a reverse-geometry (BE) sector instrument. The fragmentation pathways observed are generally consistent with the previously mentioned CID and photodissociation results in which $C_{3}$ loss dominates for $n<30$ and $C_{2}$ loss (indicative of their fullerene nature) dominates for $n \geq 30$. Detailed analysis of the kinetic energy release distributions (KERDs) for these processes and comparison with results from statistical phase space theory yielded estimates of the bond energies and internal excitation of the parent ions. Surprisingly, the KERDs of the fullerene cations $(n=58-62)[60]$ indicated that there 
is no reverse activation barrier for $C_{2}$ loss from any of the cluster ions (even $\mathrm{C}_{60}^{+}$) and that the data could be easily fit by $\mathrm{C}_{2}$ evaporation from a spheroidal molten drop model, thus providing no strong evidence for unique structures of these species. Similar fragmentations and KERDs were obtained by Lifshitz et al. [61, 62] for the $n=3-16$ cluster ions formed by electron ionization of overcrowded perchloro-hydrocarbons, as were reported using laser vaporization of graphite [58], suggesting similar $C_{n}^{+}$structures from dramatically different cluster sources. Smalley and co-workers [63] showed that the $C_{2}$ loss process begins to compete with thermionic emission that forms multiply charged fullerenes for large cluster sizes ( $n>200$ ).

The ionization potentials (IPs) of both the small ( $n<25)$ [64] and large $(n \geq 48)$ [65] carbon clusters were bracketed by charge-transfer reactions using FTMS. The possibility of using charge-transfer to bracket the IPs of small carbon clusters was first proposed by Marshall and co-workers [27] and McElvany [40]. Detailed studies by Bach and Eyler [64] found the IPs for small $C_{n}$ to decrease with size with large alternations for $n=7,11,15,19$, and 23 whose IPs are $-0.5 \mathrm{eV}$ lower than neighboring clusters, consistent with their enhanced abundance in the positive ion mass spectra. In contrast, the IPs of $C_{50}, C_{60}$ and $C_{70}$ were measured to be $7.61 \pm 0.1 \mathrm{eV}$ [65], which is $-0.5 \mathrm{eV}$ higher than neighboring clusters. The high IPs of the larger magic number clusters illustrate the relative stability of these species towards ionization and suggests that their high abundance in the positive ion mass spectra is not due to ease of ionization. The extremely unreactive nature of the $C_{60}$ and $C_{70}$ clusters, which are generated in high abundance in the recent macroscopic synthesis, was clearly evident in their slow charge-transfer reaction rates compared to the other clusters.

The small carbon cluster anions, $C_{n}^{-}(n<20)$, were characterized by several groups using tandem mass spectrometry. Smalley and co-workers [66] measured the electron affinities and obtained some structural information (e.g., linear to cyclic transition at $n=10$ ) on the neutrals by studying the photoelectron spectroscopy of mass-selected anions. Photodissociation studies by Deluca and Johnson [67] using tandem TOF-MS determined that $C_{3}$ loss is the preferred fragmentation for the anions as in the positive ions and that the larger clusters ( $n>13$ ) undergo electron detachment due to their cyclic structure (lower electron affinity). Similar results were obtained by McElvany [68] in the CID and ion/molecule reactions of $C_{n}^{-}(n<13)$ formed by DLV in an FTMS. Evidence was also observed for the presence of product ion isomers in the reaction of carbon clusters.

Although the availability of macroscopic quantities of $C_{60}, C_{70}$, and several higher fullerenes has resulted in detailed characterization of their chemical and physical properties with a variety of techniques, mass spectrometry studies of all sizes of carbon cluster ions continues through the use of laser vaporization sources. The gas-phase chemistry and structures of the larger clusters which have yet to be isolated in bulk quantities continues to be an area of intense research. Addition of gaseous hydrocarbons to the helium expansion in LVMB sources has been used both as a source of carbonaceous material for cluster formation [69] and also for detailed chemical reactivity studies of the neutral carbon clusters [70]. Anderson and co-workers [71, 72] have used ion beam techniques to study the energy dependence of $C_{n}^{+}(n<13)$ reactions which are consistent with the earlier results on the structures and isomers observed for the small carbon cluster ions [26, 39-41]. Bowers and co-workers [73] have measured the ion mobilities of a wide range of carbon cluster ions which can be modeled to provide structural information. The observed differences in ion mobilities confirm the linear to cyclic structural transition and the presence of isomers reported in earlier studies, in addition to providing structural information on the larger cluster ions.

\section{Synthesis of Bulk Fullerenes}

While there was a tremendous amount of information being acquired on the properties of carbon clusters, these studies were limited because the cluster production method restricted the experiments to the gas phase. Yet, the data from the experiments described above provided convincing evidence for unusual stability and unique properties of $C_{60}$. These gas-phase, and largely mass spectrometric, studies provided many interesting results but possibly the most significant impact was on a group of astrophysicists who redirected their investigations of interstellar carbonaceous material. In the fall of 1990 a collaborative effort between Wolfgang Krätschmer at the Max Planck Institute in Heidelberg and Donald Huffman at the University of Arizona resulted in the first production of macroscopic quantities of $C_{60}$ [74]. By simply resistively heating graphite in the presence of helium, they obtained soot that upon IR analysis contained four narrow absorptions above the background continuum [75]. The frequencies of the absorptions correlated reasonably well with the four IR-active modes predicted by theory for the symmetric icosahedral structure of $C_{60}$. Without these theoretical studies (made possible for such a large species by its high symmetry), which were motivated in large part by the intriguing mass spectrometric data described above, these lines may not have been readily assigned and the production of macroscopic quantities of $C_{60}$ would have remained a dream for just a few researchers. Extraction of this soot with benzene was found to yield significant amounts of $\mathrm{C}_{60}$. One of the first techniques applied to the analysis of the soot extract was mass spectrometry. Both SIMS and EI were used to provide unambiguous identification of $C_{60}$ and $C_{70}$ as the 
major components. The latter method yielded cleaner mass spectra and a ratio of $C_{60} / C_{70}$ of approximately 50. The announcement of this fantastic discovery at a conference in Konstanz, Germany, in September 1990, permanently changed the terminology from carbon clusters to fullerenes and initiated one of the broadest, most exciting, and rapidly moving areas of scientific research. In essence, the mass spectrometry studies of gas-phase species combined with the discovery of a simple synthetic method yielded nothing less than a new form of carbon and a new area of science. While the large quantities of fullerenes would allow the application of many more analytical methods, mass spectrometry continues to play a crucial role in revealing further unexpected and unprecedented properties.

\section{Characterization of Fullerenes in Soot}

Several groups quickly confirmed the results of

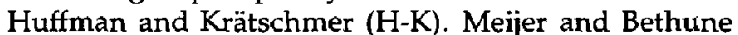
[76] at IBM-Almaden used laser desorption of soot produced by the $\mathrm{H}-\mathrm{K}$ method with subsequent photoionization of desorbed neutrals to confirm the presence of fullerenes. It is noteworthy that this group had demonstrated, just prior to the H-K discovery, that fullerenes produced by laser ablation of graphite could be deposited via the gas phase onto another surface and analyzed by laser desorption mass spectrometry [77]. In addition, Kroto and co-workers [78] at the University of Sussex used UV-vis and IR spectroscopy, ${ }^{13} \mathrm{C}$ NMR and mass spectrometry in their confirmatory studies. With an $m$-nitrobenzyl alcohol matrix, they used fast atom bombardment (FAB) to generate mass spectra of the raw soot extract as well as that of selected fractions of chromatographically separated material. A report from an interdisciplinary group of scientists at UCLA provided a detailed description of soot preparation, extraction and yield of soluble material and chromatographic (HPLC) separation [79]. This was followed by in-depth analyses of both $C_{60}$ and $C_{70}$ by NMR, absorption spectroscopy, and mass spectrometry. This work provided a direct comparison of $\mathrm{EI}, \mathrm{FAB}$ and laser desorption (LD) ionization techniques. Both FAB and LD of the benzene or toluene extract yielded mass spectra with predominately $C_{60}^{+}$and $C_{70}^{+}(\sim 85 / 15)$ with very low abundances of smaller or intermediate species. In contrast, $70-\mathrm{eV}$ EI mass spectra ubtained of the vapor thermally desorbed at $-350^{\circ} \mathrm{C}$ yields, in addition to $\mathrm{C}_{60}^{+}$and $\mathrm{C}_{70}^{+}$multiply charged molecular ions and species corresponding to $C_{58}^{+}, C_{56}^{+}, C_{54}^{+}$and $C_{52}^{+}$(Figure 4), which were shown to be fragmentation products of $C_{60}^{+}$by ionization energy (and corroborative laser fuence) dependence studies. The fust evidence of larger fullerenes was reported for $C_{84}$ in a preliminary note, which was later expanded in several reports on the observation and identification of $C_{76}$,

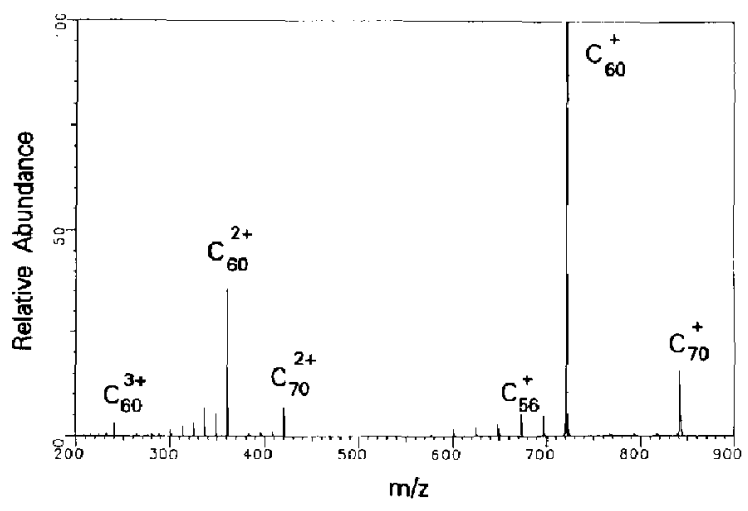

Figure 4. Electron ionization mass spectrum of a fullerene mixture, which was extracted into toluene from arc-generated graphitic soot and thermally desorbed at approximately $350^{\circ} \mathrm{C}$.

$\mathrm{C}_{78}, \mathrm{C}_{84}, \mathrm{C}_{90}, \mathrm{C}_{94}$ and $\mathrm{C}_{70} \mathrm{O}[80,81]$. Smalley and co-workers [82] developed a "contact arc" method to produce large amounts of fullerenes that were characterized by a larger interdisciplinary group at Rice by using NMR, FTIR, cyclic voltammetry, and mass spectrometry [83]. The soot generated in benzene/oxygen flames has also been extracted and analyzed by EI mass spectrometry [84] indicating that higher $C_{70} / C_{60}$ ratios are produced in these flames than in the methods described above using graphite. In the first attempt to form a solid-state derivative of $C_{60}$ [83], the Birch reduction reaction was used to hydrogenate $C_{60}$, and EI mass spectrometry was used to identify $\mathrm{C}_{60} \mathrm{H}_{36}$ as the product (as well as a $\mathrm{C}_{60} \mathrm{H}_{18}$ ) and further studies showed the reversibility of the process. These were the initial studies on solid-state fullerenes and provided strong evidence for the utility and importance of mass spectrometry in the elucidation of their properties, which will be discussed further in the next section.

\section{Chemical Ionization and Ion/Molecule Reactions}

While it was realized early on that EI was the simplest and most straightforward method, relative to FAB and LD, to generate fullerene ions, chemical ionization (CI) was attempted later to provide more information on the purity of the HPLC fractions. Beyond this practical application, the $C I$ results would serve to open up a broad area of characterization of fullerene ion/molecule chemistry and gas-phase adduct formation. The Exxon group furst used $\mathrm{CI}$ with methane reagent gas and observed proton transfer to yield $\mathrm{C}_{60} \mathrm{H}^{+}$and electron capture to give $\mathrm{C}_{60}^{-}$[85]. In addition, it was observed that $C_{60}^{-}$was 15 times more abundant than $\mathrm{C}_{60} \mathrm{H}^{+}$, indicating a highly favorable electron capture probability that is consistent with the 
measured high electron affinity [35]. This work prompted more detailed studies of positive and negative ion $\mathrm{CI}$ of fullerenes.

Nearly simultaneous research at NRL [86] and Purdue [87] yielded significant new insights on fullerene ion/molecule chemistry. The positive ion (PI) methane $\mathrm{CI}$ mass spectrum of thermally desorbed fullerenes from a toluene soot extract is shown in Figure $5 \mathrm{a}$. In addition to the protonated fullerene molecules (mostly $\mathrm{C}_{60}, \mathrm{C}_{70}, \mathrm{C}_{76}, \mathrm{C}_{78}$, and $\mathrm{C}_{84}$ ), adducts of the fullerenes with $\mathrm{C}_{2} \mathrm{H}_{5}$ are observed in methane $\mathrm{Cl}$. Similarly, with isobutane $\mathrm{PI} / \mathrm{CI}$ fullerene- $\mathrm{C}_{4} \mathrm{H}_{9}$ adduct ions are observed. In contrast to the $\mathrm{PI} / \mathrm{CI}, \mathrm{NI} / \mathrm{CI}$ produced abundant fullerene anions of not only those $C_{n}$ species observed as $\mathrm{C}_{n} \mathrm{H}^{+}$but also $\mathrm{C}_{m}$ with $n=86$ to 124 as shown in Figure 5b. It was noted that the $C_{60} / C_{70}$ ratio in these $\mathrm{NI} / \mathrm{CI}$ mass spectra is $2 / 1$, compared to $5 / 1$ from PI/EI studies, and this was attributed to a larger electron capture cross section for $C_{70}$. It is worthwhile noting here that recently it has been shown by two groups that a doubly charged negative ion of $C_{60}, C_{60}^{2-}$, can be observed from laser desorption of the soot extract in an FTMS [88, 89]. Interest-
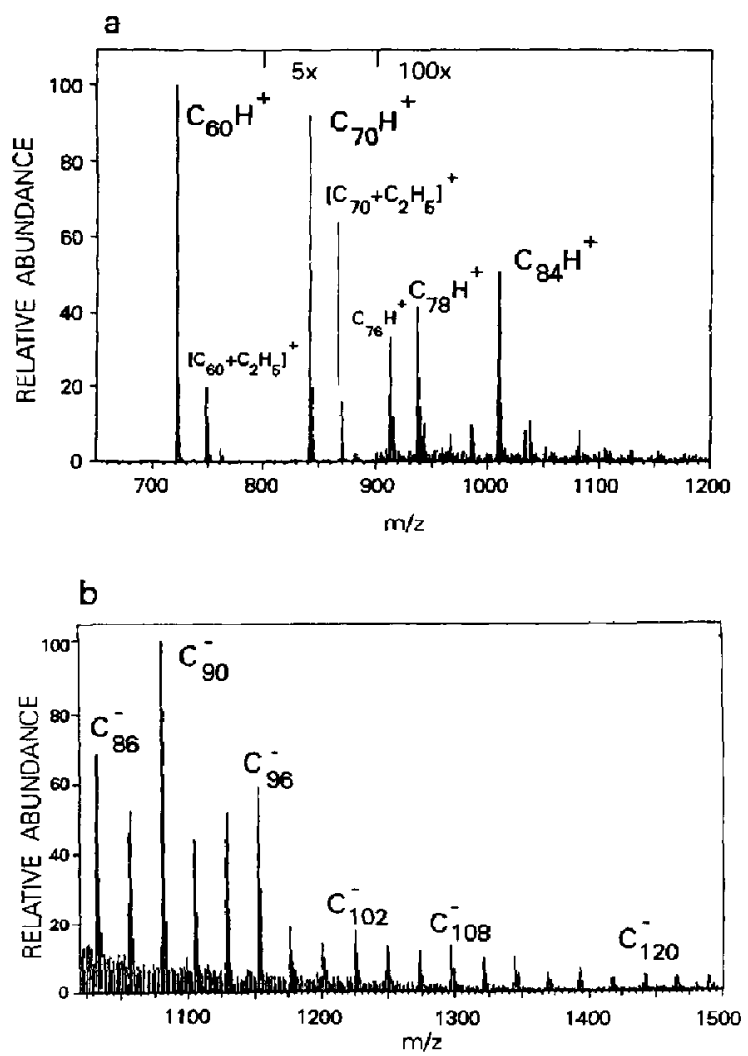

Figure 5. (a) Methane positive ion chemical ionization and (b) methane negative ion chemical ionization mass spectra of a fullerene mixture (ref 86 ). ingly, these doubly-charged anions are not observed in $\mathrm{NI} / \mathrm{Cl}$ or by thermal electron capture.

Proton-transfer bracketing methods with FTMS were used to determine the proton affinities of $C_{60}$ and $C_{70}$ to be greater than or equal to that of ammonia $(204 \mathrm{kcal} / \mathrm{mol})$ and less than that of hexamethylbenzene (207 kcal/mol) [86]. This high proton "affinity, combined with an observed high stability (with respect to $\mathrm{CID}$ ) of $\mathrm{C}_{60} \mathrm{H}^{+}$, provide some supporting evidence for a postulation that this species is responsible for an unexplained diffuse interstellar absorption band [2].

In addition to the above $\mathrm{CI}$ studies, there have been other investigations of ion/molecule reactivity of fullerenes. Squires and co-workers [90] used a flowing afterglow-triple quadrupole instrument to study reactions of $C_{60}^{-}$and $C_{70}$. The fullerene anions were found to be essentially unreactive with a variety of acids, including water, isopropanol, trifluoroethanol, and trifluoroacetic acid, which is consistent with the unreactive nature of the positive ions observed in the earlier studies [28, 33]. However, these anions are reactive with $\mathrm{NO}_{2}$, resulting in the formation of $\mathrm{C}_{60} \mathrm{NO}_{2}^{-}$and $\mathrm{C}_{70} \mathrm{NO}_{2}^{-}$. In a different study, Freiser and co-workers [91] were able to form complexes of $\mathrm{C}_{60}$ with several metal ions, including $\mathrm{Fe}, \mathrm{Co}, \mathrm{Ni}, \mathrm{Cu}$, $\mathrm{Rh}, \mathrm{La}$, and VO, via gas-phase association between $\mathrm{M}^{+}$and $\mathrm{C}_{60}$ in an FTMS. Subsequent CID of the complexes resulted in simple cleavage of $\mathrm{M}-\mathrm{C}_{60}$ with the charge retained on the lower IP species (usually $\mathrm{M}^{+}$), suggesting that the metal binds externally to $C_{60}$ in these ion/molecule reactions. This fragmentation pathway is in contrast to that observed for endohedral $\mathrm{C}_{60} \mathrm{M}^{+}$formed in an LVMB source [33] in which photodissociation results in $C_{2}$ losses.

\section{Dissociations}

The ease of production of molecular ions of $\mathrm{C}_{60}$ facilitated studies of the fragmentation behavior. Indeed, in the first extensive report of the EI mass spectrometry of fullerenes, CID was also studied [92]. Kilovolt collisions of $\mathrm{C}_{60}^{+}$(formed by EI of the thermally desorbed soot extract) with helium resulted in fragmentation to yield smaller even-numbered fullerene cations, $C_{n}^{+}$, from $n=58$ to 44 (for example, sce Figure 6). This distribution of fragment ions was found to be the same as that produced directly in the EI process and is similar to the earlier photodissociation results [33]. In addition, CID of $\mathrm{C}_{60}^{2+}$ yielded only $\mathrm{C}_{n}^{2+}$, for even-numbered $n$ from 58 to 42 , and no $C_{n}^{+}$, in contrast to the analogy made to polycyclic aromatic hydrocarbons (PAHs) which undergo charge-separation reactions. Harrison and co-workers [93] investigated the CID of fullerene ions in more detail and noted anomalous abundances of $C_{50}^{+}$from $C_{60}^{+}$and $\mathrm{C}_{60}^{+}$from $\mathrm{C}_{70}^{+}$in the distribution of smaller fullerene fragment ions, consistent with the early photodissoci- 
ation studies [32], and that dissociations of multiply charged species $\left(\mathrm{C}_{60}^{2+}, \mathrm{C}_{70}^{2+}\right.$ and $\left.\mathrm{C}_{60}^{3+}\right)$ also produced fragment ions corresponding to successive $C_{2}$ losses. On consideration of the energetics of the collision and dissociations observed, it was suggested that neutral fragments larger than $C_{2}$ are lost, which is still an unresolved issue. Such fragmentations were also observed to occur upon collisions with xenon in a triple quadrupole instrument, although the remarkable stability of $C_{60}^{+}$was noted in that relatively high energies (>190 eV) with multiple collision conditions were required to observe fragmentation [86, 87]. Finally, using oxygen as the target gas in $\mathrm{keV}$ collisions, charge stripping of $\mathrm{C}_{60}^{+}$is observed to form $\mathrm{C}_{60}^{2+}$ (see Figure 6). This phenomenon was studied further by Lifshitz et al. [94] who measured the translational energy loss associated with this charge-stripping reaction. This experiment yielded a value of $12.25 \pm 0.5$ $\mathrm{eV}$ as the energy required to remove a second electron from $\mathrm{C}_{60}$. Gross and co-workers [95] used the same general method to measure the second ionization energies of $C_{60}, C_{70}$ and $C_{84}$ to be 11.9, 12.0, and $12.0 \pm 0.5 \mathrm{eV}$, respectively. These results from kilovolt CID studies are significantly different from NRL studies of ion/molecule charge-transfer bracketing experiments in an FTMS, which yielded a value of $9.7 \pm 0.5 \mathrm{eV}[96]$ from the $\mathrm{C}_{60}^{2+}+\mathrm{N} \rightarrow \mathrm{C}_{60}^{+}+\mathrm{N}^{+}$reaction. This method may result in a low value if kinetic barriers exist in the exit channel; however, a subsequent VUV photoionization study [97] favors the lower charge-transfer value.

In addition to $\mathrm{CID}$ and photodissociation, some research has focused on surface-induced dissociation (SID) of $\mathrm{C}_{60}^{+}$. Whetten and co-workers [98] constructed a tandem TOF mass spectrometer to study the fundamentals of cluster/surface interactions. Unlike other cluster ions (e.g., $\mathrm{Si}_{n}^{+}$and alkali halides) or molecular ions (e.g., hydrocarbons), $C_{60}^{+}$does not dissociate to a significant extent at collision energies of $200-300 \mathrm{eV}$

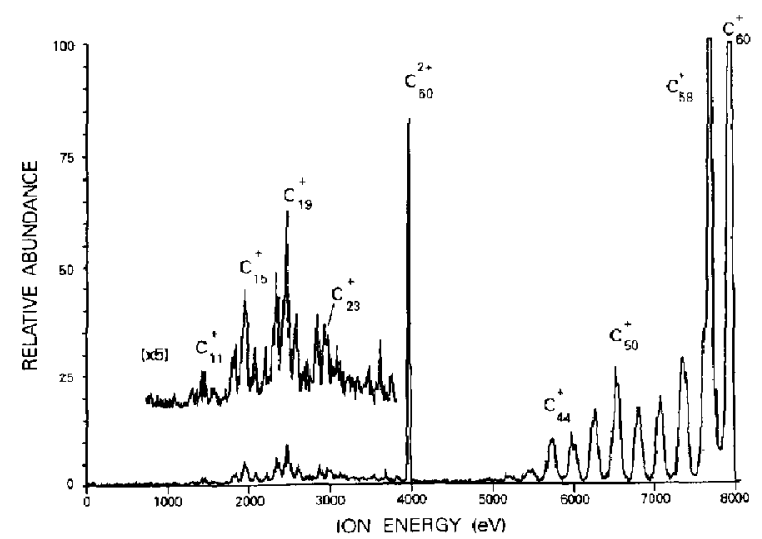

Figure 6. 8-keV $\mathrm{C}_{60}^{+} / \mathrm{O}_{2}$ collision-induced dissociation/massanalyzed ion kinetic energy spectrum (ref 101). on a silicon or graphite target. This observation was confirmed by others using tandem quadrupole ion/surface collision devices, which in addition showed more fragmentation from $C_{60}^{2+}[99]$. The postulation that the stability of $C_{60}^{+}$to SID is due to the unusual stability and "resilience" of $C_{60}$ is supported by recent measurements of surface-scattered neutrals and velocity and energy distributions of the scattered $\mathrm{C}_{60}^{+}[100]$.

More extensive studies of the dissociations of fullerenes have yielded further evidence of the unusual nature of these species. The detailed analysis of the fragmentation of $\mathrm{C}_{60}^{+}$by kilovolt collisions with oxygen showed that in addition to the smaller fullerene fragment ions $\left(\mathrm{C}_{n}^{+}, n=38-58\right)$, small carbon cluster ions $\left(\mathrm{C}_{x}^{+}, x=7-25\right)$ are also produced (see Figure 6) [101]. Although the abundance distribution of the CID-generated fragment ions is very similar to that observed using photodissociation [32], the fragmentation mechanism is not fully understood. It is interesting that the abundance distribution of $\mathrm{C}_{x}^{+}$produced by fragmentation is also similar to that generated directly by laser vaporization of graphite (i.e., anomalously high abundances of $\mathrm{C}_{11}^{+}, \mathrm{C}_{15}^{+}, \mathrm{C}_{19}^{+}$, and $\mathrm{C}_{23}^{+}$). In the same study, CID of multiply charged fullerene cations was found to yield not only a charge stripping product but the electron capture product as well. In addition, $C I D$ of $\mathrm{C}_{60}^{2+}$ was found to yield mostly smaller $C_{n}^{2+}$ as reported previously; however. there were also significant abundances of singly charged fragment ions. While the mechanism for these dissociations is unclear, similar lower charge state product ions were observed from CID of the triply and quadruply charged $C_{60}$. It was also noted that there are large shifts from the expected kinetic energy values of the fragment ions, due to significant energy uptake of the parent $C_{60}^{+}$.

\section{Endohedral Complex Formation}

It was during a similar CID study of $\mathrm{C}_{60}^{+}$that an unprecedented and unexpected phenomenon was observed. Schwarz and co-workers reported in the Fundamentals Workshop at the 1991 ASMS Conference that $8-\mathrm{keV}$ collisions of helium and $\mathrm{C}_{60}^{+}$(and $\mathrm{C}_{70}^{+}$), in a four-sector mass spectrometer, resulted in production of not only smaller fullerene fragment ions $\left(\mathrm{C}_{n}^{+}, n=\right.$ $48-58$ ) but also another series of ions corresponding to $\left[\mathrm{C}_{n}+4\right]^{+}$(Figure 7a) [102]. When the collision gas was changed to ${ }^{3} \mathrm{He}$ the second series of ions shifted to $\left[C_{n}+3\right]^{+}$, suggesting that these fragment ions corresponded to adducts of helium and the smaller fullerene fragments of $\mathrm{C}_{60}^{+}$.

These unusual and unexpected observations prompted further studics by several groups. Ross and Callahan [103] used a hybrid tandem mass spectrometer $(\mathrm{BEqQ})$ to detect and identify unambiguously $\mathrm{C}_{60} \mathrm{He}^{+}$through measurement of its $\mathrm{m} / \mathrm{z}$ and kinetic 
a

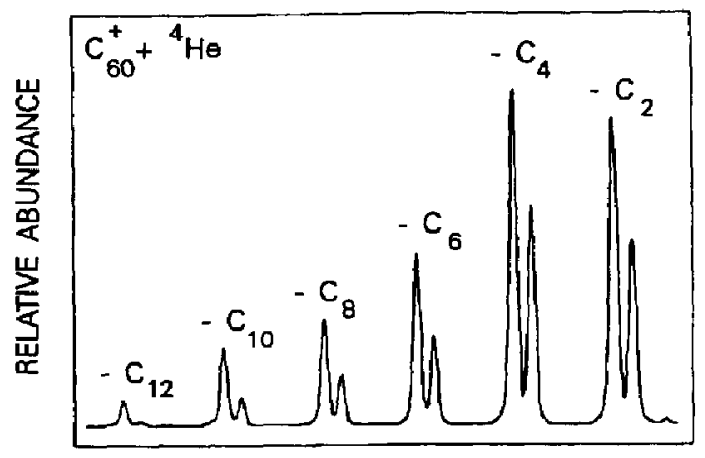

$\mathrm{m} / 2$

b

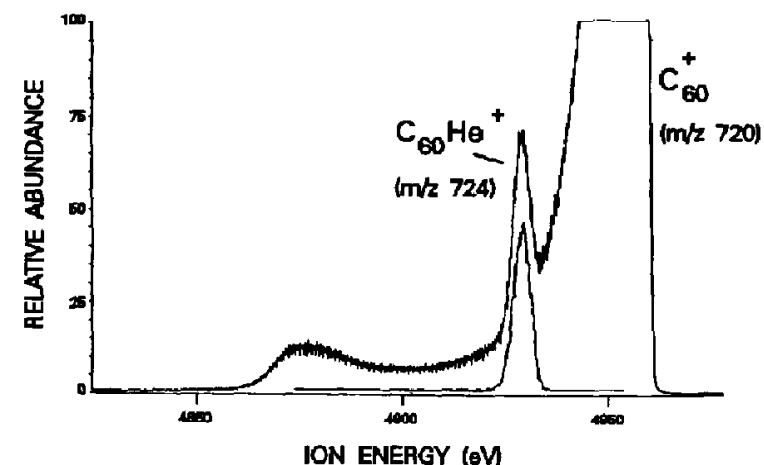

Figure 7, (a) 8-keV $\mathrm{C}_{60}^{+} / \mathrm{He}$ collision-induced dissociation mass spectrum showing the fullerene fragment ions, $C_{n}^{+}$, and helium/fullerene fragment ions, $\mathrm{C}_{n} \mathrm{He}^{+}$, with $n=58,56,54,52$ and 50 (Reprinted with permission from ref. 102. Copyright $1991 \mathrm{VCH}$ ) and (b) 5-keV C + / $/$ He collision-induced dissociation mass-analyzed ion kinetic energy spectrum showing the broad distribution of $C_{60}^{+}$energies, a narrow peak at $4926 \mathrm{eV}$ and a "foot" at $4870 \mathrm{eV}$. The narrow range scan under the main plot shows the kinetic energy spectrum resulting from additional mass-selection of $\mathrm{m} / \mathrm{z} 724\left(\mathrm{C}_{60} \mathrm{He}^{+}\right)$by the quadrupole (refs 103, 107).

energy (Figure $7 b$ ). It was shown that the shift in the kinetic energy of $\mathrm{C}_{60} \mathrm{He}^{+}$from that of $\mathrm{C}_{60}^{+}$corresponded to the center-of-mass collision energy. In addition, subsequent $\mathrm{CID}$ of $\mathrm{C}_{60} \mathrm{He}^{+}$resulted in product ions that retained the helium atom, thus providing strong evidence for the helium being inside of the $\mathrm{C}_{60}$ cage. The $\mathrm{C}_{60} \mathrm{He}^{+}$was subsequently reported by Schwarz and co-workers [104], and by Gross and co-workers [105] using three- and four-sector tandem mass spectrometric methods. Schwarz and coworkers [106] reported similar results from helium collisions with $\mathrm{C}_{60}^{2+}$ and $\mathrm{C}_{60}^{3+}$. Gross and co-workers [95] observed that $C_{70}^{+}$and $C_{84}^{+}$also form endohedral complexes with helium and then extended this work considerably by showing that $\mathrm{C}_{60}^{+} / \mathrm{D}_{2}$ collisions yield
$\mathrm{C}_{60} \mathrm{D}^{+}$and $\mathrm{C}_{60} \mathrm{D}_{2}^{+}$(but no $\mathrm{C}_{n} \mathrm{D}_{x}^{+}$), $\mathrm{C}_{60}^{+} /$Ne collisions produce $\mathrm{C}_{60} \mathrm{Ne}^{+}$and $\mathrm{C}_{n} \mathrm{Ne}^{+}$and $\mathrm{C}_{60}^{+} / \mathrm{Ar}$ collisions result in some unusual $\mathrm{C}_{n} \mathrm{Ar}^{+}$species (with odd $n$ values). Although these latter endohedral complexes are difficult to observe with conventional four sectors because of large energy losses, they were detected with a new instrument that is designed to transmit product ion beams with large energy spreads.

Recent work has involved comparison of the experimental measurements with molecular dynamics simulation of $\mathrm{C}_{60} / \mathrm{He}$ collisions [107]. This study has revealed insights into the impulsive nature of these collisions and explains the position of the broad peak ("foot") in the tail of the $\mathrm{C}_{60}^{+}$kinetic energy distribution (see Figure $7 b$ ). Research such as this on mass spectrometrically produced endohedral complexes of fullerenes, using different sized "guests" and "hosts" promises to be an exciting and increasingly active area.

\section{Mass Spectrometry of Fullerene Derivatives}

In addition to the above applications to the characterization of the gas-phase chemistry and properties of fullerenes, mass spectrometry has been used to analyze derivatives of fullerenes, which are synthesized as bulk materials. As mentioned above, the first derivatization reaction attempted on $\mathrm{C}_{60}$ was the Birch reduction, and EI mass spectrometry was employed to identify the products [83]. The first fullerene derivative to be extracted from arc-generated graphite soot and isolated by chromatography was identified by mass spectrometry to be $\mathrm{C}_{70} \mathrm{O}$ [81]. This was the first example of a new fullerene-based material to come directly from the fullerene synthesis processes and would give rise to many other such species as will be discussed later. Another derivatization reaction that was suggested early on was fluorination. Selig et al. [108] used EI mass spectrometry to analyze the products of $C_{60}$ and $C_{70}$ reactions with $F_{2}$. The abundant species observed were $\mathrm{C}_{60} \mathrm{~F}_{36}^{+}$and $\mathrm{C}_{70} \mathrm{~F}_{40}^{+}$, and CID revealed fragmentations of these ions by elimination of $\mathrm{F}, \mathrm{CF}_{3}$ and $\mathrm{C}_{2} \mathrm{~F}_{5}$. Holloway et al. [109] used mass spectrometry, in addition to infrared and NMR spectroscopies, to identify the reaction products from fluorine gas interacting with solid $C_{60}$. FAB/MS using an $m$-nitrobenzylamine matrix produced a distribution of $\mathrm{C}_{60} \mathrm{~F}_{x}$ species, peaking at $\mathrm{C}_{60} \mathrm{~F}_{6}$ and $\mathrm{C}_{60} \mathrm{~F}_{42}$. Bausch et al. [110] showed that fullerenes could be reduced using lithium metal and sonication to form polyanions, which then could be methylated by reaction with methyl iodide. Field ionization mass spectrometry was used to detect a distribution of methylated fullerenes, with 1 to 24 methyl groups.

Researchers at Purdue have investigated several different types of fullerene derivatives using mass spectrometry. First, they noticed that the electron 
attachment (negative ion) mass spectra of the soot extract showed, in addition to the "pure" fullerenes (e.g., $C_{60}^{-}$and $C_{70}$ ), adduct ions corresponding to additions of $\mathrm{O}, \mathrm{OH}, \mathrm{CH}_{2}$, and $\mathrm{CH}_{3}$ [111]. In addition, they found that photochemistry was involved in the derivatization because irradiation of fullerene solutions in air with ultraviolet light resulted in significant increases in the abundances of $\mathrm{C}_{n} \mathrm{O}_{x}^{-}$and $\left(\mathrm{C}_{n} \mathrm{O}+\right.$ $\left.\left(\mathrm{CH}_{2}\right)_{x}\right)^{-}$. In a second study, aromatic molecules (benzene, toluene, xylene, anisole, and bromobenzene) were observed to add to $C_{60}$ or $C_{70}$ [112]. Negative ion desorption $\mathrm{CI}$ with ammonia reagent gas was used to identify the adducts produced by refluxing the fullerenes in an aromatic solvent with excess $\mathrm{FeCl}_{3}$. The stability of these adducts was demonstrated with CID studies.

\section{Internally and Intrinsically Doped Fullerenes}

The research described above illustrates derivatization of fullerenes by attaching chemical species to the outside of the cage. Another method of modifying fullerenes externally is accomplished by doping $C_{60}$ films with alkali metal atoms to give a new superconducting fulleride salt [113]. Fullerenes can also be doped by substituting an atom of an element other than carbon for one or more of the carbon atoms that constitute the fullerene cage. Smalley and co-workers, [114] showed that laser vaporization of a boron nitride/graphite disk yields boron-doped fullerenes such as $\mathrm{C}_{60-n} \mathrm{~B}_{n}^{+}$with $n=0$ to 6 . While photodissociation experiments revealed these new species to be as resistant to fragmentation as pure fullerenes, reactions with ammonia in the FTMS cell showed significant acidic behavior of the boron atoms. These ion $/$ molecule reactions effectively titrate the boron reactive sites on the doped fullerenes to produce $\mathrm{C}_{60-n} \mathrm{~B}_{n}\left(\mathrm{NH}_{3}\right)_{n}^{+}$species, while the pure fullerenes are unreactive. This study stimulated further laser/mass spectrometric attempts to synthesize fullerenes doped in different ways.

Recalling the earlier experiments in which metalfullerene adduct ions were formed by laser vaporization and studied with photodissociation/mass spectrometry [33], Smalley's group recently has succeeded in producing macroscopic quantities of internally doped fullerenes [115]. Laser vaporization of graphite impregnated with $\mathrm{La}_{2} \mathrm{O}_{3}$ or $\mathrm{LaB}_{6}$ in a flow of inert gas and heated to $1200^{\circ} \mathrm{C}$ produces soot that upon sublimation forms a film consisting of a series of La@C with $n=60,70,74$, and 82 . (The $\mathrm{M@O} \mathrm{C}_{n}$ nomenclature denotes that $M$ is located inside the carbon cage.) The La@ $\mathrm{C}_{82}$ species can be concentrated by toluene extraction and was shown to be stable with respect to moisture and air as shown by the laser desorption mass spectrum in Figure 8 . Recent $x$-ray photoelectron and electron spin resonance spectroscopic analy-

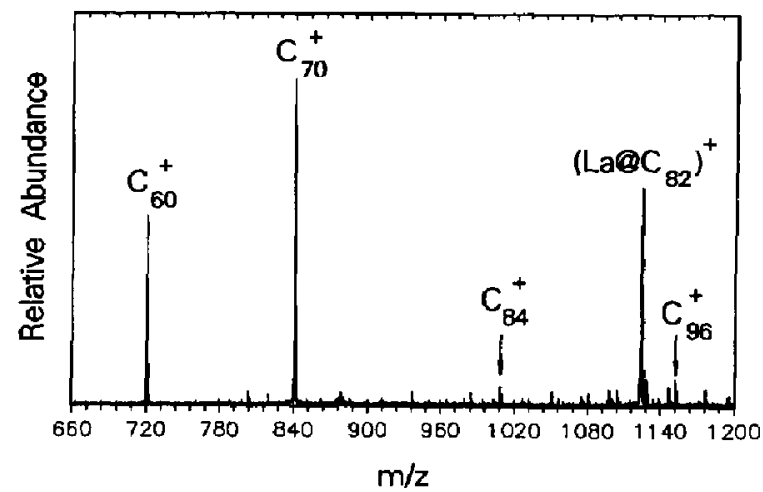

Figure 8. Fourier transform mass spectrum of the toluene extract of fullerene material produced by laser vaporization of a graphite and $\mathrm{La}_{2} \mathrm{O}_{3}$ composite rod, demonstrating that $\mathrm{La} @ \mathrm{C}_{82}$ is air stable and produced in macroscopic quantities. (Reprinted with permission from ref. 115. Copyright 1991 American Chemical Society.)

ses of these modified fullerenes have provided more evidence for these being endohedral complexes [116, 117]. In addition, ion/molecule reactivity and fragmentation studies in the FTMS have shown that the $\left(\mathrm{La} @ \mathrm{C}_{n}\right)^{+}$and $\left(\mathrm{Y} @ \mathrm{C}_{n}\right)^{+}$species are unreactive to oxidation and highly stable $[115,118]$, unlike externally bound metal-fullerene complexes [91]. Possibly the most important result from these studies is observation of larger fullerenes with more than one atom doped inside of the cage. As has been recently shown with lanthanum/ and yttrium/graphite mixtures. laser vaporization produces not only $\mathrm{M@C} \mathrm{C}_{n}$ but also $\mathrm{M}_{2} @ \mathrm{C}_{n}$, and $\mathrm{M}_{3} @ \mathrm{C}_{n}$. It is important to note that these latter species increased in abundance depending on laser fluence and time of irradiation in such a way that suggests that laser-induced coalescence reactions in or on the sample are responsible for the multiply doped fullerenes $[115,118]$. This work may form the basis for a novel synthetic method for doped fullerene materials. However, it is certain that mass spectrometry will continue to play a key role in characterizing the new materials based on the third form of carbon.

\section{Closing Remarks}

We have attempted to summarize the role that mass spectrometry has contributed in both the discovery and characterization of gas-phase carbon clusters and fullerenes and also its continued role in the characterization of pure and derivatized fullerene materials. The availability of bulk quantities of these materials for only one year has resulted in the numerous mass spectrometry studies described here which will undoubtedly be greatly surpassed by the publication date of this review. Those active or interested in keeping up to date on all areas of fullerene research would be advised to obtain a recent copy of Prof. Richard Smalley's Buckminsterfullerene bibliography 
[119] and/or subscribe to the electronic mail "bucky news service" [120].

\section{Acknowledgments}

We acknowledge the Office of Naval Research for support of our research. We thank our colleagues at NRL in the many collaborative studies on carbon clusters and fullerenes discussed in this review. We also thank the various authors for consent to use their figures in this review.

\section{References}

1. Smalley, $\mathrm{R}$. $\mathrm{E}$. The Sciences 1991, 31, 22.

2. Kroto, H. W; Allaf, A. W.; Balm, S. P. Chem. Rev. I991, 91, 1213.

3. Curl, R. F.; Smalley, R. E. Scientific American 1991, 265, 54.

4. Weltner, W.; Van Zee, R. J. Chem. Rev. 1989, 89, 1713.

5. Mattauch, J.; Ewald, H.; Hahn, O.; Strassmann, F., Z. Phys. 1943, 120, 598.

6. Dörnenburg, E.; Hintenberger, H. Z. Naturforsch 1959, $14 A, 765$.

7. Dörnenburg, E.; Hintenberger, H.; Franzen, J. Z. Naturforsch 1961, 532 .

8. Honig, R. E. J. Chem. Phys. 1954, 22, 126.

9. Drowart, J.; Burns, R. P.; DeMaria, G.; Inghram, M. G. J. Chem. Phys. 1959, 31, 1131.

10. Honig, R. E. Adv. Mass Spectrom. 1963, 2, 25.

11. Berkowitz, J.; Chupka, W. A. J. Chem. Phys. 1964, 40, 2735.

12. Fürstenau, N.; Hillenkamp, F.; Nitsche, R. Int. J. Mass Spectrom. Ion Phys. 1979, 31, 85.

13. Dietz, T. G.; Duncan, M. A.; Powers, D. E.; Smalley, R. E. J. Chem. Phys. 1981, 74, 6511.

14. Rohlfing, E. A.; Cox, D. M.; Kaldor, A. J. Chem. Phys. $1984,81,3322$.

15. Bloomfield, L. A.; Geusic, M. E.; Freeman, R. R.; Brown, W. L. Chem. Phys. Lett, 1985, 121, 33.

16. Kroto, H. W.; Heath, J. R.; O'Brien, S. C.; Curl, R. F.; Smalley, R. E. Nature 1985, 318, 162.

17. Heath, J. R.; O'Brien, S. C.; Zhang, Q.; Liu, Y; Curl, R. F.; Kroto, H. W.; Tittel, F. K.; Smalley, R. E. I. Am. Chem. Sac. 1985, 107, 7779 .

18. Cox, D. M.; Reichmann, K. C.; Kaldor, A. J. Chem. Phys. 1988, 88, 1588.

19. Cox, D. M,; Trevor, D, J.; Reichmann, K. C.; Kaldor, A. J. Am. Chem. Soc. 1986, 108, 2457

20. Liu, Y.; O'Brien, S. C.; Zhang, Q.; Heath, J. R.; Tittel, F. K.; Curl, R. F.; Kroto, H. W.; Smalley, R. E. Chem. Phys. Lett. 1986, 126, 215.

21. Hahn, M. Y.; Honea, E. C.; Paguia, A. J.; Schriver, K. E,; Camarena, A. M.; Whetten, R. L. Chem. Phys. Lett. 1986, $130,12$.

22. O'Brien, S. C.; Heath, J. R.; Kroto, H. W.; Curl, R. F.; Smalley, R. E. Chern. Phys. Lett. 1986, 132, 99.

23. Zhang, Q. L.; O'Brien S. C.; Heath, J. R.; Liu, Y.; Curl, R. F.; Kroto, H. W.; Smalley, R. E. I. Phys. Chem. 1986, 90, 525.

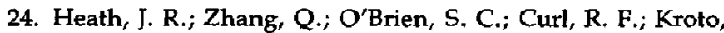
H. W.; Smallcy, R. E. J. Am. Chem. Soc. 1987, 109, 359.

25. O'Keefe, A.; Ross, M. M.; Baronavski, A. P. Chem. Phys. Lett. 1986, 130, 17 .

26. McElvany, S. W.; Creasy, W. R.; O'Keefe, A. J. Chem. Phys. 1986, 85, 632.

27. Knight, R. D.; Walch, R. A.; Foster, S. C.; Miller, T. A.; Mullen, S. L.; Marshall, A. G. Chem. Phys. Lett. 1986, 129, 331.
28. MeElvany, S. W.; Nelson, H. H.; Baronavski, A. P.; Watson, C. H.; Eyler, J. R. Chem. Phys. Lett. 1987, 134, 214.

29. Gerhardt, P.; Löffler, S.; Homann, K. H. Chem. Phys. Lett. 1987, 137, 306

30. Frenklack, M.; Ebert, L. B. J. Phys. Chem. 1988, 92, 561.

31. Ebert, L. B. Science 247, 1990, 1468.

32. O'Brien, S. C.; Heath, J. R.; Curl, R. F.; Smalley, R. E. J. Chem. Phys. 1988, 88, 220.

33. Weiss, F. D,; Elkind, J. L.; $O^{\prime}$ Brien, S. C; Curl, R, F,; Smalley, R. E. J. Am. Chem. Soc. 1988, 110, 4464.

34. Maruyama, S.; Anderson, L. R.; Smalley, R. E. Rev. Sci. Inst. 1990, 61, 3686.

35. Yang, S. H.; Pettiette, C. L; Conceicao, J-; Cheshnovsky, O.; Smalley, R. E. Chem. Phys. Lett. 1987, 139, 233.

36. Heath, J. R.; Curl, R. F.; Smalley, R. E. J. Chem. Phys. $1987,87,4236$.

37. Geusic, M. E.; Mcllrath, T. J.; Jarrold, M. F.; Bloomfield, L. A.; Freeman, R. R.; Brown, W. L. I. Chem. Phys. 1986, 84, 2421.

38. Gcusic, M. E.; Jarrold, M. F.; Mcllrath, T. J.; Frecman, R. R.; Brown, W. L. J. Chem. Phys. 1987, 86, 3862.

39. McElvany, S. W.; Dunlap, B. I.; O'Keefe, A. J. Chem. Phys. 1987, 86, 715.

40. McElvany, S. W. I. Chem. Phys. 1988, 89, 2063.

41. Parent, D. C.; McElvany, S. W. J. Am. Chem. Soc. 1989, 111, 2393.

42. Zakin, M. R.; Brickman, R. O.; Cox, D. M.; Kaldor, A. J. Chem. Phys. 1988, 88, 3555.

43. Hantrick, Y.; Taylor, S,; Lemire, G. W.; Fu, Z. W.; Shui, J. C.; Morse, M. D. 1. Chem. Phys. 1988, 88, 4095.

44. Elkind, J. L.; Weiss, F. D.; Alford, J. M.; Laaksonen, R. T.; Smalley, R. E. J. Chem. Phys. 1988, 88, 5215.

45. Creegan, K. M.; Jarrold, M. F. J. Am. Chem. Soc. 1990, 112 , 3768 .

46. Jarrold, M. F.; Bower, J. E.; Creegan, K. M. J. Chem. Phys. $1989,90,3615$.

47. Creasy', W. R.; Brenna, J. T. Chem. Phys. 1988, 126, 453.

48. Creasy, W. R.; Brenna, J. T. J. Chem. Phys. 1990, 92, 2269.

49. Campbell, E. E. B.; Ulmer, G.; Hasselberger, B,; Busmann, H. G.; Hertel, I. V. J. Chem. Phys. 1990, 93, 6900.

50. Feld, H.; Zurmühlen, R.; Leute, A.; Benninghoven, A. J. Phys. Chem. 1990, 94, 4595.

51. Lineman, D. N.; Somayajula, K. V.; Sharkey, A. G.; Hercules, D. M. I. Phys. Chem, 1989, 93, 5025.

52. Greenwood, P. F.; Strachan, M. G.; El-Nakat, H. J.; Willett, G. D.; Wilson, M. A.; Attalla, M. I. Fuel 1990, 69, 257.

53. So, H. Y.; Wilkins, C. L. J. Phys. Chem. 1989, 93, 1184.

54. Rubin, Y.; Kahr, M.; Knobler, C. B.; Diederich, F.; Wilkins, C. L. J. Am. Chem. Soc. 1991, 113, 495.

55. Creasy, W. R. J. Chem. Phys. 1990, 92, 7229.

56. Yang, Y. A.; Xia, P.; Junkin, A. L.; Bloomfield, L. A. Phys. Reo. Lett. 1991, 66, 1205.

57. Radi, P. P.; Bunn, T. L.; Kemper, P. R.; Molchan, M. E.; Bowers, M. T. J. Chem. Phys. 1988, 88, 2809.

58. Radi, P. P.; Rincon, M. E.; Hsu, M. T.; Brodbelt-Lustig, J.; Kemper, P.; Bowers, M. T. I. Chem. Phys. 1989, 93, 6187.

59. Radi, P. P.; Hsu, M. T.; Brodbelt-Lustig, J.; Rincon, M.; Bowers, M. T. J. Chem. Phys. 1990, 92, 4817.

60. Radi, P. P.; Hsu, M. T.; Rincon, M. E.; Kemper, P. R.; Bowers, M. T. Chem. Phys, Lett. 1990, 174, 223.

61. Lifshitz, C.; Peres, T.; Kababia, S.; Agranat, I. Int. J. Mass Spectrom. Ion Proc. 1988, 82, 193.

62. Lifshitz, C.; Peres, T.; Agranat, I. Int. J. Mass Spectrom. Ion Proc. 1989, 93, 149.

63. Maruyama, S.; Lee, M. Y,; Haufler, R. E.; Chai, Y.; Smalley, R. E. Z. Phys, D. 1991, 19, 409.

64. Bach, S. B. H.; Eyler, J, R. I. Chem. Phys. 1990, 92, 358.

65. Zimmerman, J. A.; Eyler, J. R.; Bach, S. B. H.; McElvany, 
S. W. J. Chem. Phys. 1991, 94, 3556.

66. Yang, S.; Taylor, K. J.; Craycraft, M. J.; Conceicao, J.; Pettiette, C. L.; Cheshnovsky, O.; Smalley, R. E. Chem. Phys. Lett. 1988, 144, 431.

67. Deluca, M. J.; Johnson, M. A. Chern. Phys. Lett. 1988, 152, 67.

68. McElvany, S. W. Int. J. Mass Spectrom. Ion Proc. 1990, 102, 81.

69. Harano, A.; Kinoshita, J.; Koda, S. Chem. Phys. Lett. 1990, $172,219$.

70. Rohlfing, E. A. I. Chem. Phys. 1990, 93, 7851.

71. Hintz, P. A.; Sowa, M. B.; Anderson, S. L. Chem. Phys, Iett. 1991, 777, 146.

72. Sowa, M. B.; Hintz, P. A.; Anderson, S. L. J. Chem. Phys. $1991,95,4719$.

73. von Helden, G.; Hsu, M. T.; Kemper, P. R.; Bowers, M. T. 1. Chem. Phys. 1991, 95, 3835.

74. Krätschmer, W.; Lamb, L. D.; Fostiropoulos, K.; Huffman, D. R. Nature 1990, 347, 354

75. Krätschmer, W.; Fostiropoulos, K.; Huffman, D. R. Chem. Phys. Lett. 1990, 170, 167.

76. Meijer, G.; Bethune, D. S. Chem. Phys. Lett. 1990, 175, 1.

77. Meijer, G.; Bethune, D. S. T. Chem. Phys. 1990, 93, 7800.

78. Taylor, R.; Hare, J. P.; Abdul-Sada, A. K.; Kroto, H. W. I. Chem. Soc. Chem. Commun. 1990, 1423.

79. Aije, H.; Alvarez, M. M.; Anz, S. J.; Beck, R. D.; Diederich, F.; Fostiropoulos, K.; Huffman, D. R.; Krätschmer, W.; Rubin, Y.; Schriver, K. E.; Sensharma, D.; Whetten, R. L. 1. Chem. Pliys. 1990, 94, 8630 .

80. Whetten, R. L.; Alvarez, M. M.; Anz, S. J.; Schriver, K. E.; Beck, R. D.; Diederich, F. N.; Rubin, Y.; Ettl, R.; Foote, C. S.; Darmanyan, A. P.; Arbogast, J. W. Mat. Res. Soc, Prec. $1991,206,639$.

81. Diederich, F. N.; Ettl, R.; Rubin, Y.; Whetten, R. L.; Beck, R.; Alvarez, M. M.; Anz, S.; Sensharma, D.; Wudl, F.; Khemani, K. C.; Koch, A. Science 1991, 252, 548.

82. Haufler, R. E.; Chai, Y.; Chibante, L. P. F.; Conceicao, J.; Lin, C.; Wang, L. S.; Maruyama, S.; Smalley, R. E. Mat. Res. Soc. Symp. Proc. 1991, 206, 627

83. Haufler, R. E.; Conceicao, I.; Chibante, L. P. F.; Chai, Y.; Byrne, N. E.; Flanagan, S.; Haley, M. M.; O'Brien, S. C.; Pan, C.; Xiao, Z.; Billups, W. E.; Ciufolini, M. A.; Hauge, R. H.; Margrave, J. L.; Wilson, L. J.; Curl, R. F.; Smalley, R. E. J. Phys. Chem. 1990, 94, 8634.

84. Howard, J. B.; McKinnon, J. T.; Makarovsky, Y.; Lafleur, A. L.; Johnson, M. E. Nature 1991, 352, 139.

85. Cox, D. M.; Behal, S.; Disko, M.: Gorun, S.; Greaney, M.; Hsu, C. S.; Kollin, E.; Miliar, J.; Robbins, J.; Robbins, W.; Sherwood, R.; Tindall, P. I. Am. Chem. Soc. 1991, 113, 2940.

86. McElvany, S. W، Callahan, J. H. J. Phys. Chem. 1991, 95, 6186.

87. Ben-Amotz, D.; Cooks, R. G.; Dejarme, L.; Gunderson, J. C.; Hoke, S. H.; Kahr, B.; Payne, G. L.; Wood, J. M Chem. Phys. Lett. 1991, 183, 149.

88. Limbach, P. A.; Schweikhard, L.; Cowen, K. A.; McDermott, M. T.; Marshall, A. G.; Coe, J. V. J. Am. Chem. Soc. 1991, 113, 6795 .

89. Hettich, R. L.; Compton, R. N.; Ritchie, R. H. Phys. Rev. Lett. 1991, 67, 1242

90. Sunderlin, L. S.; Paulino, J. A.; Chow, J.; Kahr, B.; BenAmotz, D.; Squires, R. R. J. Am. Chem. Soc. 1991, 113, 5489

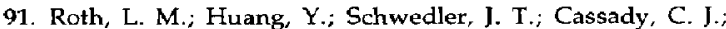
Ben-Amotz, D.; Kahr, B.; Freiser, B. S. I. Am. Chem. Soc
1991, 113, 6298; Huang, H.; Freiser, B. S. J. Am. Chem. Soc. 1991, 113, 8186 .

92. Luffer, D. R.; Schram, K. H. Rapid Connm. Mass Spectrom. $1990,4,552$.

93. Young, A. B.; Cousins, L.; Harrison, A. G. Rapid Comm. Mass Spectrom. 1991, 5, 226.

94. Lifshitz, C.; Iraqi, M.; Peres, T.; Fischer, J. Rapid Comm. Mass Spectrom. 1991, 5, 238.

95. Caldwell, K. A.; Giblin, D. E.; Gross, M. L. J. Am. Chem. Soc. 1991, in press

96. McElvany, S. W.; Ross, M. M.; Callahan, J. H. Mat. Res. Soc. Symp. Proc. 1991, 206, 697.

97. Yon, R. K.; Ruscir, B.; Berknwitz, J. J. Chom. Phys., in press.

98. Beck, R. D.; St. John, P.; Alvarez, M. M.; Diederich, F.; Whetten, R. L. J. Phys. Chem. 1991, 95, 8402.

99. Wysocki, V. H.; Callahan, J. H., unpublished results.

100. Whetten, R. L., unpublished results.

101. Doyle, R. J.; Ross, M. M. J. Phys. Chem. 1991, 95, 4945.

102. Weiske, T.; Bohme, D. K.; Hrusak, J.; Krätschmer, W.; Schwarz, H. Ang. Chem. Int. Ed. Engl. 1991, 30, 884.

103. Ross, M. M.; Callahan, J. H. J. Phys. Chem. 1991, 95, 5720.

104. Weiske, T.; Bohme, D. K.; Schwarz, H. J. Phys. Chem. 1991, 95, 8451.

105. Caldwell, K. A.; Giblin, D. E.; Hsu, C. S.; Cox, D.; Gross, M. L. J. Am. Chem. Soc. 1991, 113, 8519.

106. Weiske, T.; Hrusak, J.; Bohme, D. K.; Schwarz, H. Chem. Phys. Lett. 1991, 186, 459

107. Mowrey, R. C.; Ross, M. M.; Callahan, J. H., submitted to J. Phys. Chem.

108. Selig, H.; Lifhsitz, C.; Peres, T.; Fischer, J. E.; Smith, A. B.; McGhie, A. R.; Romanow, W. J.; McCauley, J. P. J. Am. Chem. Soc. 1991, 113, 5475.

109. Holloway, J. H.; Hope, E. G.; Taylor, R.; Langley, J.; Avent, A. G.; Dennis, J.; Hare, J. P.; Kroto, H. W.; Walton, D. R. M. I. Chem, Sac. Chem, Commun. 1991, 14, 966.

110. Bausch, J. W.; Surya Prakash, G. K.; Olah, G. A.; Tse, D. S.; Lorents, D. C.; Bae, Y. K.; Malhortra, R. J. Am. Chem. Soc. 1991, 113, 3205.

111. Wood, J. M.; Kahr, B.; Hoke, S. H.; Dejarme, L.; Cooks, R. G.; Ben-Amotz, D. J. Am. Chem. Soc. 1991, 113, 5907.

112. Hoke, S. H.; Molstad, J.; Payne, G. L.; Kahr, B.; BenAmotz, D.; Cooks, R. G. Rapid Comm. Mass Spectrom. 1991, 5,472 .

113. Hebard, A. F,; Rosseinsky, M. J.; Haddon, R. C.; Murphy, D. W.; Glarum, S. H.; Palstra, T. T. M.; Ramirez, A. P.; Kortan, A. R. Nature 1991, 350, 600.

114. Guo, T.; Jin, D.; Smalley, R. E. J. Phus. Chem. 1991, 95, 4948.

115. Chai, Y.; Guo, T.; Jin, C.; Haufler, R. E.; Chibante, L, P. F.; Fure, J.; Wang, L.; Alford, I. M.; Smalley, R. E. J. Phys. Chem. 1991, 95, 7564.

116. Weaver, J. H.; Chai, Y.; Kroll, G. H.; Jin, C.; Ohno, T. R.; Haufler, R. E.; Guo, T.; Alford, J. M.; Conceicao, J.; Chibante, L. P. F.; Jain, A.; Palmer, G; Smalley, R. E. Nature 1991, submitted.

117. Johnson, R. D.; de Vries, M. S., Salem, I.; Bethune, D. S.; Yannoni, C. S. Nature 1991, submitted.

118. McElvany, S. W., unpublished results.

119. Prof. R. E. Smalley, Rice Quantum Institute and Departments of Chemistry and Physics, Rice University, Houston, TX 77251 .

120. Bucky update e-mail address: (bucky@sol1.lrsm.upenn.edu) 